\title{
Espelhos pós-coloniais, imagens coloniais: discursos e representações sobre os portugueses em livros didáticos angolanos de História elaborados no pós-independência (1979-2000)
} Anderson Ribeiro Oliva*

Resumo: Com base neste artigo, tem-se como intenção analisar parte dos discursos e das representações elaborados sobre os portugueses em manuais escolares de História produzidos e utilizados em Angola no período que se segue à independência política do país, em 1975. O texto apresentado, fruto de uma investigação de maior dimensão, partiu dos referenciais teóricos vinculados aos Estudos Africanos, aos Estudos Culturais e Pós-Coloniais, para identificar a forma como parte da produção didática angolana recepcionou, fomentou e divulgou o entendimento acerca da identidade nacional e das relações coloniais e pós-coloniais com os portugueses. A partir dos pressupostos elencados, selecionamos para uma reflexão inicial dois livros produzidos entre 1979 e 2000 destinados à $4^{\mathrm{a}}$ classe de escolaridade.

Palavras-chave: Identidades. Estudos Pós-Coloniais. Angola. Ensino. Colonização.

\footnotetext{
* Professor do Departamento de História da Universidade de Brasília-UnB. Doutor em História pela UNB. E-mail: oliva@unb.br.
}

Anos 90, Porto Alegre, v. 21, n. 40, p. 227-249, dez. 2014 
Espelhos pós-coloniais, imagens coloniais...

\section{Introdução}

Descobrimo-nos a nós mesmos, sem dúvida, e compreendemos uma coisa: nosso passado contém elementos de dominação e danação externas, ciclos de conquistas por forças árabes, forças ocidentais e forças globalizantes. Intervenções estrangeiras ocorreram durante todo o curso de nosso passado, trazendo maldições e lançando as bases de nossos conflitos, nossa pobreza, nosso sofrimento. Assim como nos descobrimos a nós mesmos, também o fizemos quando outros descobriram nossos recursos e roubaram tudo sobre o que puseram a mão. Ao nos roubar, primitivizaram-nos. O colonialismo e o capitalismo não apenas nos privaram, mas nos diminuíram e nos emascularam. Tais legados tornam-se parte da Africana que temos de desvelar. Já não nos confrontamos apenas com o descobrir, mas também com o defender-nos e o revidar. (FALOLA, 2007, p. 20)

A produção de discursos - textuais ou imagéticos - acerca dos outros e sobre nós mesmos tem sido uma poderosa ferramenta empregada por ideólogos, cientistas e educadores na construção das percepções que as sociedades possuem de suas próprias identidades ou das alteridades relacionais. Ao longo das últimas décadas, com efeitos, às vezes, mais negativos do que positivos, os textos fílmicos, a literatura, a circulação de notícias cotidianas pelos meios de comunicação e a produção de manuais escolares têm servido para o reforço de estereótipos e para a sedimentação de ideias distorcidas sobre o convívio entre os mais diversos grupos humanos.

De dentro destas experiências discursivas, emerge uma atenção necessária para os cenários pós-coloniais (africanos, asiáticos, americanos ou europeus). As tensas, violentas e desgastantes relações estabelecidas nos decursos coloniais, anticoloniais e pós-coloniais deixaram cicatrizes físicas, emocionais, simbólicas e identitárias de complexa revelação e mensuração. Talvez, alguns dos efeitos produzidos por essas marcas - que precisam de remédios e prognósticos mais eficazes do que os prescritos até o momento - sejam a perma-

Anos 90, Porto Alegre, v. 21, n. 40, p. 227-249, dez. 2014 
nência ou reincidência de práticas contaminadas pelo racismo, pela xenofobia e pela intolerância religiosa, principalmente quando pensamos as ondas migratórias em direção à Europa e o processo de refundação identitária que os europeus desde então se viram forçados a dimensionar. No entanto, em sentido contrário, o olhar dos ex-colonizados em direção aos ex-colonizadores merece igualmente uma atenção das investigações e das reflexões dos cientistas sociais, assim como suas tessituras autoperceptivas internas, igualmente complexas, multifacetadas e densas.

A partir dessas considerações iniciais, este artigo tem como intenção principal analisar alguns dos discursos e algumas das representações elaborados sobre os portugueses em manuais escolares de História produzidos e utilizados em Angola no período seguinte à independência política do país, conquistada em 1975. Resultado de uma investigação de maior dimensão, o percurso agora seguido partiu dos referenciais teóricos vinculados aos Estudos Africanos, aos Estudos Culturais e Pós-Coloniais, para identificar a forma como parte dos discursos escolares recepcionou, fomentou e divulgou, a partir das imagens e ideias que circulavam nos livros de História, o entendimento acerca de suas identidades e das relações coloniais e pós-coloniais com os portugueses. Selecionamos para uma reflexão inicial dois livros didáticos angolanos produzidos entre 1979 e 2000 destinados à $4^{\text {a }}$ classe de escolaridade ${ }^{1}$. Apesar da distância de mais de duas décadas entre as duas publicações, parte dos seus textos confundem-se, assim como as representações produzidas sobre os angolanos, os portugueses e as suas relações.

O fato da guerra civil angolana ainda estar em curso no período em destaque (seu término ocorre apenas em 2002) talvez aponte para a permanência dos discursos de resistência ou rejeição aos portugueses. Talvez, a longa duração do governo do MPLA, tenha tencionado as percepções sobre esse Outro/ex-colonizador na mesma direção. Para além disso, e muito provavelmente embebendo a produção e circulação de ideias sobre os portugueses, esteja o fato de que os imaginários de parte significativa dos angolanos ainda operassem dentro do que se tem afirmado ser a permanência das narrativas e literaturas coloniais e anticoloniais no contexto pós-colonial. A 
Espelhos pós-coloniais, imagens coloniais...

descolonização dos cenários mentais e dos pensamentos é tarefa a ser realizada de forma contínua dentro das sociedades europeias e africanas. Como lembra-nos Paul Gilroy,

O passado colonial ainda não digerido pode intervir em ambos os lados da fronteira cultural, tornando a situação política actual mais perniciosa e inflexível. A reconciliação com as conseqüências do extinto poder colonial, há muito devida, não é apenas uma maneira de tornar visíveis os problemas gerados pela hierarquia racial; é também uma via para retirar estas questões difíceis do domínio oficial da cultura, introduzindo-as no universo da política. (GILROY, 2007, p. 178-179)

Nesse caso, é necessário que os discursos produzidos pelas novas gerações de angolanos e portugueses não esqueçam as marcas de um passado recente, sulcado pelas explorações coloniais, pelo racismo e pela resistência às suas estruturas e aos seus mecanismos. Mas, ao mesmo tempo, o presente exige um esforço de dialogar com esse passado e reinventar as percepções do que somos atualmente e de quem são os outros no agora. A construção de sociedades equânimes em suas tessituras internas e marcadas pelo princípio de um convívio respeitoso e dialógico entre os indivíduos é uma postura teórica, epistêmica e filosófica que sinaliza em direção a uma nova inscrição coletiva da condição humana, que se espera emergir no atual século.

Os fluxos de imigrantes africanos (e também de asiáticos e sul-americanos), que mesmo antes do pós-colonial que começaram a inundar as antigas metrópoles com um choque de humanidade, redefiniram as modernas, dicotômicas e essencializadas identidades europeias. Os afro-portugueses (ou luso-africanos), os afro-caribenhos, os anglo-africanos, os afro-franceses (franco-africanos), entre outras dezenas de novas roupagens identitárias, sacudiram a Europa com as adesões discursivamente frágeis às teses do multiculturalismo. As veladas euforias do sucesso das novas sociedades nacionais europeias no pós-colonial ruíram junto com o Estado do Bem-Estar Social, os atentados terroristas do começo do milênio e

Anos 90, Porto Alegre, v. 21, n. 40, p. 227-249, dez. 2014 
com a grave crise econômica que atingiu o continente no final da última década. Casos de racismo, xenofobia e islamofobia forçaram os europeus a reconhecer o fracasso de suas políticas de combate a essas chagas sociais que sobreviveram e se reinventaram após o fim das experiências coloniais.

Em África, o pós-colonial foi construído a partir de uma complexa simbiose envolvendo os discursos sobre uma nova identidade africana (tendo como origem o pan-africanismo e a negritude), a construção dos jovens Estados-Nação, as novas identidades nacionais, a inserção de uma África autônoma na modernidade e, por fim, a escrita de uma agenda anti-imperialista vagamente articulada. Parece certo que grande parte das histórias e dos textos literários produzidos no contexto anticolonial e pós-independência refutam, reagem e tornam-se dependentes das histórias imperiais europeias em África, mesmo quando visitam experiências históricas anteriores a essa fenda relacional que foi o imperialismo/colonialismo. Como defende Stuart Hall,

\begin{abstract}
Os momentos de independência e pós-colonial, nos quais essas histórias imperiais continuam a ser vivamente retrabalhadas, são necessariamente, portanto, momentos de luta cultural, de revisão e de reapropriação. Contudo, essa reconfiguração não pode ser representada como uma "volta ao lugar onde estávamos antes, já que [...] sempre existe algo no meio". (HALL, 2009, p. 34)
\end{abstract}

No caso angolano, a essa conjuntura, soma-se o transcurso de uma década sem os conflitos que acompanharam o país desde o início dos anos 1960. Essa Nova Angola convive com a explosão do crescimento econômico, elevados índices de desigualdade social e miséria, além de uma distância temporal, talvez, suficiente para pensar suas faces identitárias sem o espelho do português colonizador como reflexo a desconstruir.

Nossas reflexões emergem deste mosaico de considerações para observar a forma como textos escolares participam ou participaram da construção de discursos identitários nacionais em Angola, tingidos pela presença fantasmagórica da lembrança do colonizador.

Anos 90, Porto Alegre, v. 21, n. 40, p. 227-249, dez. 2014 
Dessa forma, partiremos nessa incursão conduzidos pela perspectiva informada pelo teórico indo-britânico Homi Bhabha, para quem a demanda da identificação "[...] é sempre o retorno de uma imagem de identidade que traz a marca da fissura no lugar do Outro de onde ela vem” (BHABHA, 2003, p. 76).

\section{Entre discursos pós-coloniais, como pensar a nação moderna africana?}

Parece ser mais ou menos consensual que os nacionalismos, inclusive os africanos, emergem da construção de projetos políticos acomodados em discursos que intentam tornar homogêneos os sentidos da nação ou do pertencimento a uma identidade nacional. Portanto, as narrativas nacionais sustentam-se ou nutrem-se das memórias das glórias, humilhações, derrotas e vitórias elencadas a partir de um passado historicizado, que se confunde com os mitos de origem e com as tradições que funcionam como sistemas de símbolos e de representação que deveriam ser compartilhados por todos (BARBOSA, 2011).

No entanto, Kwame Appiah lembra-nos de que boa parte dos Estados africanos pós-coloniais "[...] tinha uma gama bastante ampla de culturas e línguas dentro de suas fronteiras [...]" e que, "passado o momento de coesão contra" o colonizador, "[...] o registro simbólico da união nacional confrontou-se com a realidade [...]" de suas diferenças (APPIAH, 1997, p. 226-227).

Em quase todos os lugares [...] os novos Estados reuniram povos que falavam línguas diferentes, tinham tradições religiosas e noções de propriedade diferentes e, em termos políticos (e, sobretudo, hierárquicos), tinham graus diferentes de integração, muitas vezes radicalmente diversos. No fim da descolonização européia - quando mais de $80 \%$ da população da África negra encontrava-se nos dez maiores países africanos ao sul do Saara e 2\% estavam nos dez menores -, nem mesmo os Estados com populações mais diminutas, de modo geral, eram etnicamente homogêneos. (APPIAH, 1997, p. 226)

Anos 90, Porto Alegre, v. 21, n. 40, p. 227-249, dez. 2014 
O desconcertante é que a partir de um cenário marcado por um denso mosaico de populações, identidades, culturas e sistemas econômicos e ecológicos, quatro países europeus (França, Inglaterra, Portugal e Bélgica) construíram "a geografia nacional da África contemporânea", sendo que a língua colonial "[...] continuou a ser a língua de governo depois da independência" (APPIAH, 1997, p. 226). Mais do que a língua, a presença colonial europeia em África deixou um claro resíduo epistêmico nas formas de pensar ou de explicar os contextos africanos.

Toyin Falola destaca que este seria um dos efeitos mais concretos da colonização, que, para além das estruturas da violenta exploração econômica e humana, produziu uma sofisticada estrutura de colonização das mentes e dos processos epistemológicos. Os mecanismos de brutalidade e de estruturação do mundo colonial ou a adesão à modernidade europeia poderiam drenar as ideias e percepções da existência produzidas nas línguas maternas e o nativo tornar-se-ia "colonizado na memória do estrangeiro". Sendo assim "[...] a forma como o conhecimento é produzido passa a ser controlada, moldada pela visão de mundo do colonizador. É um conhecimento moldado pelo contexto colonial de sua aquisição" (FALOLA, 2007, p. 22).

O pós-colonial transveste-se não apenas de um aparelhamento teórico, mas de uma roupagem que informa, pela proximidade temporal ou pela semelhança de determinadas estruturas e práticas, um conjunto de experiências que se segue e dialoga intensamente com o status colonial.

Neste caso seria preciso destacar que a questão (ou o sentimento) anticolonial não se extinguiu com os atos de independência. A denúncia dos atos de violência e exploração praticados pelo colonizador continuava viva, tanto nas memórias e nos discursos que não podiam deixar cair no esquecimento essas impactantes experiências, como nos discursos que tentavam construir uma nova percepção identitária sobre o ser africano, ser angolano, e sobre o outro europeu, no caso, o português. O problema é que essa nova identidade continuava a ser, pelo menos em parte, produzida pelo silencioso e torturante diálogo com as imagens do colonizador que refletiam ou emergiam do espelho das lembranças do passado 
colonial. Como alerta Mbembe, ainda nos anos 1980 e 1990, percebiam-se claros movimentos no continente que esboçavam "uma junção entre o velho imaginário da 'revolução' e do 'anticolonialismo', a velha temática anti-imperialista, com as teses nativistas" (MBEMBE, 2001, p. 191).

Dessa forma, o período fronteiriço ao fim da presença colonial europeia em África revela um contexto dramático de ruptura com o passado colonial - e com todos os estigmas que ele representava e defendia em relação aos africanos - e de continuidade com algumas de suas estruturas - materiais e imateriais. Para Appiah

[...] a aparente simplicidade da administração colonial gerou nos herdeiros das nações pós-coloniais a ilusão de que o controle do Estado lhes permitiria, com a mesma facilidade, lograr seus objetivos muito mais ambiciosos. [...] Só que esse fora concebido para administrar objetivos restritos. Quando se voltou para as tarefas de um desenvolvimento maciço da infra-estrutura [...], bem como para o ensino primário universal e a imensa ampliação dos serviços de saúde e de expansão agrícola, ele se revelou aquém da tarefa. (APPIAH, 1997, p. 230)

Em parte, a crítica apresenta-se à produção ou, para alguns, à reprodução distorcida da modernidade europeia no processo de montagem dos Estados-Nação em África e, consequentemente, sua infiltração pelos discursos de pertencimento nacional. O que aguardava Angola quando o último soldado português embarcou de volta para a antiga Metrópole? Que projetos de Estado, de nação e de cooperação interna existiam? Quais modelos para organizar as cidades, a produção econômica, estabelecer o diálogo com os outros Estados africanos, estruturar os sistemas de saúde, educação e infraestruturas? Talvez, as modernidades africanas, ou mesmo a angolana, instauradas naquele momento histórico específico já fossem divergentes da modernidade imposta pelo Estado colonial, resultando de uma adesão a modelos e práticas novos ou inéditos. Talvez, não. Ana Lúcia Sá, em inspirada análise acerca do pensamento pós-colonial africano, sugere uma importante pista acerca da constituição dos discursos e das práticas naquilo que se definiu como "pós-colônia".

Anos 90, Porto Alegre, v. 21, n. 40, p. 227-249, dez. 2014 
É desta maneira que na pós-colónia se segue a distinção entre o que ou quem é ser e quem não o é, anotando-se uma semelhança entre o discurso colonial e o pós-colonial. A este respeito, à pós-colónia associa-se a ideia de nação a construir e o discurso colonial ainda subsistente. A linguagem de imposição ocidental que o conceito de nação opera leva à consideração de que o pós-colonialismo ainda não conseguiu ultrapassar a centralidade e a quase obrigatoriedade de que África tem este caminho da construção da nação a seguir. (SÁ, 2010, p. 4-5)

De alguma forma, ser angolano resulta de uma projeção ou associação a uma identidade coletiva tardiamente inventada, fruto das dinâmicas relacionais do passado vivenciado por dezenas de sociedades na África Central, mas, apenas afirmado na oposição da figura do colonizador. De alguma forma, as linhas relacionais que associam passados e presentes, memórias e tradições, identidades e identificação foram encampadas por uma substância originada pela demanda de poder deixada pelo colonizador ou pelo desejo simplesmente de ocupar o lugar deixado por este. Ideologias divergentes, projetos em conflito, particularidades regionais sucumbiram ou viraram fantoches da lógica de ocupar e se perpetuar no controle dos Estados-Nação. Achille Mbembe descreve esses sentimentos e sentidos do colonialismo e do pós-colonialismo de forma mais competente, vejamos:

Mais decisivamente, por mais "doentio" que possa parecer, o colonialismo como fenômeno mental e material exerceu uma forte sedução sobre os africanos. Esta atração foi tanto material, como moral e intelectual. Possibilidades ostensivas de mobilidade ascendente foram prometidas pelo sistema colonial. Se tais promessas realmente foram cumpridas, é algo que não está em questão. Como uma fábrica de ficções refratada e infinitamente reconstituída, o colonialismo gerou mútuas utopias e alucinações partilhadas pelos colonizadores e pelos colonizados. (MBEMBE, 2001, p. 190)

Anos 90, Porto Alegre, v. 21, n. 40, p. 227-249, dez. 2014 
O pós-colonial, nesse caso, transveste-se não apenas de um aparelhamento teórico, mas de uma roupagem que informa, pela proximidade temporal ou pela semelhança de determinadas estruturas e práticas, um conjunto de experiências que se segue e dialoga intensamente com o status colonial (SÁ, 2010, p. 5). De alguma forma, o sentimento anticolonial não se extinguiu com as independências. A denúncia dos atos de violência e exploração praticados pelo colonizador continuava viva, tanto nas memórias como nos discursos e nas novas identidades. Enfim, como desabafou Toyin Falola

Intervenções estrangeiras ocorreram durante todo o curso de nosso passado, trazendo maldições e lançando as bases de nossos conflitos, nossa pobreza, nosso sofrimento. Assim como nos descobrimos a nós mesmos, também o fizemos quando outros descobriram nossos recursos e roubaram tudo sobre o que puseram a mão. Ao nos roubar, primitivizaram-nos. O colonialismo e o capitalismo não apenas nos privaram, mas nos diminuíram e nos emascularam. Tais legados tornam-se parte da Africana que temos de desvelar. Já não nos confrontamos apenas com o descobrir, mas também com o defender-nos e o revidar. (FALOLA, 2007, p. 20)

Talvez, Falola tenha razão. No entanto, se esta perspectiva permanecer como um ingrediente vital na construção das narrativas e dos discursos nacionais africanos, os antigos colonos e colonizadores nunca se afastarão das novas identidades africanas e das construções discursivas produzidas sobre os europeus pelos africanos. Se, por um lado, o passado de brutalidades, imperialismo, escravidão, racismo e exploração não deve ser esquecido, por outro, seria justo perguntar até quando a imagem do colonizador irá conduzir a construção das autoimagens africanas. Vejamos a seguir como esse mosaico de perspectivas anteriormente descrito se insinua nas lições de História ensinadas em parte das escolas angolanas no período pós-colonial. 


\section{Discursos sobre os portugueses em manuais escolares em Angola no Pós-Colonial}

A seleção de dois livros escolares de História para a realização deste artigo não deve ser confundida apenas como uma escolha tradicional ou formal do historiador. Um dos insumos mais positivos que os estudos africanos, os estudos culturais e as teorias pós-coloniais reservam ao ofício da História é justamente a abordagem celular de objetos caracterizados pelas práticas discursivas, compreendidas apenas à luz de novas teorias ou epistemologias. Não é a recusa pelas totalidades, mas a disposição de aplicar para situações corriqueiras o denso olhar do teórico social. Mais do que isso, é claro que tenho plena consciência - e os estudos sobre a recepção, ou o que chamamos na História de apropriação ou de representações, alertam vivamente para isso - que a circulação das narrativas nacionais divulgadas nos textos escolares teve ou tem alcance limitado, mesmo para aqueles que receberam suas primeiras lições de História, ou, no caso em análise, da História de Angola, por meio de seus discursos. Apesar de tão longa ressalva, sou tentado a seguir em frente.

A ausência de uma abordagem etnográfica no presente artigo não me exime de tentar desvelar os possíveis ou hipotéticos impactos das narrativas produzidas, divulgadas e consumidas a partir da leitura desses dois livros escolares em observação. Um detalhe importante a destacar é a sobreposição de narrativas e o uso de longos trechos de textos em comum entre os manuais, o que, talvez, se explique por serem ambas as obras produzidas pelo Ministério da Educação de Angola. No entanto, eles emergem de contextos bastante distintos da história recente do país. O primeiro, Iniciação à História de Angola, foi publicado em 1979, ainda sob um tênue "calor emocional", oriundo da conquista recente da independência e, portanto, sob o império da luta anticolonial e da guerra civil que assolava o país. O segundo, História, Iniciação à História, distancia-se mais de duas décadas daquele contexto, sendo publicado em 2000, momento no qual a guerra civil angolana se encontrava em seus atos finais, com o isolamento e a perda significativa de forças por parte da UNITA de Jonas Savimbi.

Anos 90, Porto Alegre, v. 21, n. 40, p. 227-249, dez. 2014 
Espelhos pós-coloniais, imagens coloniais...

Apesar de possuir imagens, atividades e tópicos inéditos, o livro História, Iniciação à História, Ensino de Base, $4^{a}$ classe é uma espécie de reedição, com muitos trechos integrais idênticos ao primeiro livro, Iniciação à História de Angola, Ensino de Base, $4^{a}$ classe. Por isso nossas reflexões irão impactar as duas obras quase sempre em conjunto, principalmente quando os textos forem sobreposições.

A apresentação da figura do português ocorre, em ambas as narrativas, no momento da Expansão Marítimo-Comercial europeia, ou seja, a partir do século XV. Um detalhe relevante é a ausência de periodizações ou datações específicas para os primeiros séculos de contatos entre os portugueses e as sociedades, populações e formações estatais da África Central. Dessa maneira, as informações apresentadas confundem-se por um largo espaço temporal como sendo reflexos de um mesmo movimento histórico, como se houvesse um planejamento de dominação colonial estabelecido desde o começo dos contatos.

De dentro desse longo período indistinto (que parece ser um movimento circular entre os primeiros contatos, as trocas comerciais envolvendo o tráfico de escravos, a conquista colonial no final do século XIX, a experiência colonial e a guerra de independência), os portugueses aparecem nessas narrativas nacionais angolanas associados às seguintes imagens: "navegadores/aventureiros/comerciantes", "escravizadores/traficantes", "conquistadores/invasores/opressores/colonialistas", "colonizadores derrotados".

É importante notar que muitas vezes essas imagens identitárias são móveis, sobrepõem-se, transitando entre as temporalidades destacadas e os contextos históricos em questão. Muitas vezes, às identidades principais atribuídas associam-se outras, como a de missionário, militar, chefe de posto, administrador. Ao mesmo tempo em que apresentam as imagens atribuídas aos portugueses, essas narrativas dialogam com as reações africanas em relação a esse Outro europeu, em uma espécie de espelhos de expectativas para a construção de uma identidade nacional marcada pela resistência contra o invasor e pela união das sociedades africanas ou angolanas. Isso torna-se claro com a abordagem concedida às formas de resistência, às alianças, articulações ou divisões que aceleraram ou retardaram a conquista territorial por parte do "português colonialista".

Anos 90, Porto Alegre, v. 21, n. 40, p. 227-249, dez. 2014 
No primeiro conjunto de imagens produzidas sobre os portugueses, que classifiquei como "navegadores/aventureiros/comerciantes", percebe-se uma aproximação direta com as narrativas de perspectiva eurocêntrica encontradas em manuais escolares de outros países, como no Brasil e em Portugal ${ }^{2}$, quando o assunto é a expansão marítima e comercial europeia do século XV. Apesar da pequena abordagem dedicada à temática, a ênfase concedida aos portugueses no processo destaca que "[...] para chegar à Índia, era preciso dar a volta à África e, para isso, os portugueses tinham de estabelecer pontos de apoio no nosso continente [...]" além de organizarem "expediçôes navais que iam estudando a costa africana” (MINISTÉRIO DA EDUCAÇÃO DA REPÚBLICA POPULAR DE ANGOLA, 1979, p. 67, grifos nossos).

Uma dessas expedições, comandada por Diogo Cão, chegou à foz do rio Zaire em 1482, onde entrou em contacto com a população local e com os representantes do rei do Congo. Dois anos mais tarde, Diogo Cão voltou com comerciantes e padres, traziam ainda produtos para trocar: missangas, espelhos, tecidos, aguardente e outros artigos baratos. (MINISTÉRIO DA EDUCAÇÃO DA REPÚBLICA DE ANGOLA, 2000, p. 94, grifos nossos)

Como consequência do processo dessa expansão, o ato narrativo seguinte descreve os portugueses inseridos em uma longa duração, que se estende do século XV ao XIX, quando as imagens delineadas sobre os europeus os classificam como "escravizadores/ traficantes". A articulação da presença portuguesa na costa africana agora envolve a preocupação de tornar exequível a empresa colonial americana, deixando o aparecimento de uma agenda de dominação em África para algumas décadas a seguir. De qualquer forma, já há uma clara associação entre a figura do comerciante e a do traficante com ações caracterizadas pela exploração e pela violência, já que as narrativas informam que "[...] durante a época do tráfico de escravos, os portugueses e seus cúmplices foram violentos contra as populações [...] os traficantes não respeitavam sequer os estados soberanos, nem as suas leis" (MINISTÉRIO DA EDUCAÇÃO DA REPÚBLICA DE ANGOLA, 2000, p. 103, grifos nossos).

Anos 90, Porto Alegre, v. 21, n. 40, p. 227-249, dez. 2014 
Em Portugal, assim como noutros estados da Europa [...] os comerciantes estavam então interessados em explorar as riquezas do continente americano. Para isso pensaram em utilizar escravos africanos. [...] Alguns desses escravos eram apanhados por grupos de portugueses armados que assaltavam de surpresa as aldeias [...] (MINISTÉRIO DA EDUCAÇÃO DA REPÚBLICA POPULAR DE ANGOLA, 1979, p. 68-69, grifos nossos)

Nesses dois casos descritos, a crítica da narrativa nacionalista apresentada pelos textos é dirigida aos atos de violência praticados pelos traficantes e à conivência e participação dos "aristocratas do reino do Congo" (MINISTÉRIO DA EDUCAÇÃO DA REPÚBLICA POPULAR DE ANGOLA, 1979, p. 68; MINISTÉRIO DA EDUCAÇÃO DA REPÚBLICA DE ANGOLA, 2000, p. 96), tanto em relação ao comércio de escravos como sobre as relações estabelecidas com os portugueses. Essa parceria inicial "indevida", associada aos interesses comerciais, a brutalidade lusitana e a desarticulação das hegemonias políticas africanas existentes na região permitiram que os contatos derivassem da impossibilidade inicial de dominação direta para ações posteriores de conquista violenta intentada pelos europeus.

Nos primeiros tempos os portugueses não dominavam ainda
militarmente estes reinos [Congo e Ndongo]. A sua táctica foi
a seguinte: tentavam obter vantagens através do comércio,
espalhando a religião cristã e aconselhando os aristocratas e
os reis. Os padres, os comerciantes, os capitães e soldadosportugueses,
procuravam de todos os modos defender os seus interesses
e provocavam intrigas e conflitos, tentando opôr os afri-
canos uns aos outros, para enfraquecer os reinos e melhor
dominá-los. (MINISTÉRIO DA EDUCAÇÃODA REPÚBLICA
POPULAR DE ANGOLA, 1979, p. 71, grifos nossos)

Essa nova conjuntura histórica deslocaria as imagens identitárias atribuídas aos portugueses para as seguintes categorias de classificação: "conquistadores/invasores/opressores/colonialistas". Neste momento 
das narrativas, os contatos iniciais perdem o caráter transitório e de reservada autonomia para algumas "aristocracias africanas", e o português torna-se o conquistador ou o colonizador que veio usurpar e violentar a terra nativa, já que os "[...] colonialistas roubaram pois a África e nomeadamente a Angola, o seu bem mais precioso, os homens, mulheres e jovens mais válidos" (MINISTÉRIO DA EDUCAÇÃO DA REPÚBLICA POPULAR DE ANGOLA, 1979, p. 70, grifos nossos).

[...] além das pessoas que iam apanhando nas guerras KuataKuata, adquiriam por troca e levavam famílias inteiras, o pai, a mãe e os filhos, que tomavam depois rumos diferentes para nunca mais se tornarem a ver. Semeavam o medo e a insegurança, a miséria e a fome, a dor e a morte. (MINISTÉRIO DA EDUCAÇÃO DA REPÚBLICA DE ANGOLA, 2000, p. 103)

Além disso, os textos destacam que da postura conivente e cooptada, inicialmente associada à parte dos líderes africanos, o cenário histórico seguinte passa a ser caracterizado pelas ações de resistência intentadas por alguns chefes políticos em relação à presença ou ao "projeto colonial" português. Surgem nas narrativas, para além da vitimização das populações escravizadas, as figuras dos primeiros heróis angolanos (Nzinga Mbandi, Ekuikui II, Ndunduma I, Mutu-Ya-Kevela, Mandume), que do século XVII ao XX tentaram resistir e criar obstáculos à ação europeia.

Ekuikui II reinou no Bailundo [...] e teve influência notável em todo o Planalto. Quando subiu ao poder, os portugueses, já tinham dominado todo o Norte de Angola e preparavam-se para dominar o Planalto. [...] Para melhor resistir, Ekuikui II estabeleceu uma aliança sólida com Ndunduma I rei do Bié. [...] destemido, inteligente, dinâmico e defensor do povo, deixou bem vincado nos seus corações a defesa e o direito à independência dos povos. Foi sucedido por Numa II [...] O capitão português atacou a capital do Bailundo e deitou-lhe fogo. Numa II foi morto nessa batalha e aos poucos 
o Bailundo viu chegar forças militares portuguesas que foram ocupando pontos estratégicos [...]. (MINISTÉRIO DA EDUCAÇÃO DA REPÚBLICA POPULAR DE ANGOLA, 1979 , p. 80-81, grifos nossos)

No entanto, os livros defendem que apesar de algumas alianças firmadas entre as sociedades e os Estados africanos em oposição à infiltração dos portugueses e de seus interesses naqueles territórios, as diferenças associadas às divisões sociais internas daquelas sociedades os enfraqueceram, levando à ocupação colonial por parte dos portugueses.

[...] a distinção de classes, levava muitas vezes ao surgimento de conflitos entre o povo e os aristocratas, e entre estes e o rei [...]. Essas guerras traziam a destruição, o roubo e o enfraquecimento. [...] Pela mesma razão, o Ndongo foi sendo conquistado pelos portugueses. Embora estes tivessem armas de fogo, a sua conquista deveu-se, em especial, ao facto de os reinos não se terem unido para se defenderem. (MINISTÉRIO DA EDUCAÇÃO DA REPÚBLICA DE ANGOLA, 2000, p. 88)

Em parte, essas divisões societárias aparecem nas narrativas como sendo resultado do "tribalismo" e do "regionalismo" articulados com o postulado racista do colonizador. O questionamento apresentado aos leitores é explícito nesse sentido: "Qual é pois a grande lição da história de Angola? É que um povo deve ser unido contra o inimigo comum. O tribalismo, o racismo e o regionalismo, ajudam os opressores, e são armas dos exploradores contra os explorados" (MINISTÉRIO DA EDUCAÇÂO DA REPÚBLICA POPULAR DE ANGOLA, 1979, p. 86).

Várias foram as causas que levaram ao insucesso desses movimentos [de resistência]: [...] A falta de união entre os sobados e os reinos. Muitos sobas e reis preferiam ajudar os portugueses porque tinham medo de perder os seus privilégios. 
(MINISTÉRIO DA EDUCAÇÃO DA REPÚBLICA DE ANGOLA, 2000, p. 104)

Segundo os manuais escolares, a partir da tardia consolidação do domínio territorial, "os colonialistas portugueses" assumem suas potências plenas "[...] para melhor explorarem directamente as riquezas e abafar as revoltas". As principais mudanças introduzidas foram o término do comércio de escravos e a implantação do “[...] trabalho forçado, uma das características mais dominantes nas colônias portuguesas" (MINISTÉRIO DA EDUCAÇÃO DA REPÚBLICA POPULAR DE ANGOLA, 1979, p. 89, grifos nossos).

O trabalho forçado, sob a forma de contrato, consistia no seguinte: todo indígena, que não pudesse provar que trabalhara pelo menos durante seis meses no ano anterior, estava sujeito ao trabalho forçado em proveito do Estado ou de patrões privados. (MINISTÉRIO DA EDUCAÇÃO DA REPÚBLICA DE ANGOLA, 2000, p. 120)

A partir deste momento, recaem sobre os portugueses outras definições como a de "chefe de posto" ou de "administrador", figuras que, em parceria com a ação das empresas coloniais, implantavam a exploração violenta da mão de obra africana e retiravam as riquezas da terra (MINISTÉRIO DA EDUCAÇÃO DA REPÚBLICA DE ANGOLA, 2000, p. 121-122).

O fazendeiro quando precisasse de mão-de-obra requeria-a ao Governo. Por sua vez o chefe de posto, ou outro administrador da região, mandava o angariador reunir na senzala o número de homens solicitados. Estes desgraçados deixavam as suas famílias e iam para terras distantes trabalhar [...]. Em compensação recebiam um salário de miséria e maus tratos, pois, na maioria das vezes, mesmo doentes eram obrigados a trabalhar. (MINISTÉRIO DA EDUCAÇÃO DA REPÚBLICA DE ANGOLA, 2000, p. 120, grifos nossos) 
Espelhos pós-coloniais, imagens coloniais...

Neste momento as narrativas conseguem reunir todos os ingredientes necessários para a definitiva ruptura com o colonizador, ao associar a exploração das populações e a derrota das tradicionais lideranças africanas com a formação de uma massa de explorados e descontentes.

[...] a situação na colónia era precária. A população fugia maciçamente, abandonava a terra, as casas, ia ao encontro de um modo de vida melhor nos territórios vizinhos. O descontentamento era geral no País e as revoltas sucediam-se. (MINISTÉRIO DA EDUCAÇÃO DA REPÚBLICA POPULAR DE ANGOLA, 1979, p. 97).

[...] a situação na colónia era insuportável. [...] De certeza, deves estar lembrado, que ao falarmos das resistências concluímos que os povos do nosso território não aceitaram passivamente a penetração e ocupação colonial. (MINISTÉRIO DA EDUCAÇÃO DA REPÚBLICA DE ANGOLA, 2000, p. 122-123)

A conquista do território e a imposição do controle político, econômico e social pelo colonialista motivam o aparecimento dos grupos nacionalistas e independentistas. Após mais de uma década de violenta guerra em cinco frentes, potencializada pelos desgastes internos, o colonialista português foi derrotado, sendo essas as duas últimas representações elaboradas sobre sua identidade: a brutalidade colonial em sua derradeira expressão; e, a derrota do colonizador.

Por vezes, o exército colonial português, em helicópteros, localizava uma base militar ou um hospital da guerrilha, atacavam-no de surpresa e capturavam ou matavam os combatentes e populações que aí se encontrassem. (MINISTÉRIO DA EDUCAÇÃO DA REPÚBLICA DE ANGOLA, 2000, p. 126, grifos nossos)

Para nós angolanos, a luta de libertação era a única via para a obtenção da independência; morrer pela liberdade era um motivo de orgulho. Para os portugueses, morrer pela defesa da

Anos 90, Porto Alegre, v. 21, n. 40, p. 227-249, dez. 2014 
Pátria era também um motivo de orgulho, mas eles estavam convictos que não iriam ganhar a guerra porque os povos das colónias estavam determinados a prosseguir até atingirem o seu objectivo - a independência. (MINISTÉRIO DA EDUCAÇÃO DA REPÚBLICA DE ANGOLA, 2000, p. 134, grifos nossos)

\section{Imagens híbridas, identidades cruzadas}

Homi Bhabha, em seu performático diálogo com Frantz Fanon, destacou com ênfase a simbiose entre os desejos e as demandas coloniais, lembrando que o nativo, em um ato agônico e alienado pela violência colonial, tinha como uma de suas maiores ambições ocupar o lugar do colono, em uma espécie de inversão de papéis (BHABHA, 2003, p. 76). Talvez, em parte, isso tenha ocorrido com alguns poucos ex-colonizados que chegaram ao poder, à administração pública ou passaram a controlar as empresas. Porém, a maioria da população viu a transição do Estado colonial para o Estado nacional africano com desconfiança e incertezas acerca das possibilidades de melhoria em suas condições de vida.

Mais do que isso, e o que é central para minha reflexão aqui enunciada, o processo de produção discursiva das identidades, ou melhor, a tomada "da imagem psíquica da identificação" como representação da identidade é um lugar marcadamente ambivalente. Essa imagem "[...] é sempre espacialmente fendida - ela torna presente algo que está ausente - e temporalmente adiada: é a representação de um tempo que está sempre em outro lugar, uma repetição" (BHABHA, 2003, p. 84).

Nesse caso, é a repetição das imagens fantasmagóricas e híbridas do português/colono, pensado como a alteridade primordial que constitui parte significativa das imagens do angolano/colonizado que se revela uma das principais estratégias das narrativas nacionais pós-coloniais divulgadas nos livros de História analisados. Ou seja, "[...] o desejo pelo Outro é duplicado pelo desejo na linguagem, que fende a diferença entre Eu e o Outro, tornando parciais ambas as posições, pois nenhuma é auto-suficiente" (BHABHA, 2003,

Anos 90, Porto Alegre, v. 21, n. 40, p. 227-249, dez. 2014 
p. 84-85). A partir dessa perspectiva, a narrativa produzida nos livros de História parece centrar-se no argumento de que sem o colonizador não existiria o colonizado, e de que sem a figura do português colonialista, a imagem do angolano nacionalista se esvairia como fumaça ao vento.

Para além da denúncia e da lembrança sobre as brutalidades coloniais e sobre a identificação de quem foi seu principal agente, a narrativa nacionalista encontrada em ambos os manuais se alicerça na projeção da imagem do opressor para a construção imagética do angolano. Se, para o período da luta anti-imperialista, ou para os anos seguintes à independência, marcados pela longa guerra civil, as incertezas acerca das bases da composição da nação ou da identidade angolanas tornavam-se claros, os anos logo a seguir, também revelaram que nenhum dos atributos da modernidade sobre o Estado-Nação angolano pareciam ser sustentáveis. Diversidade de línguas, território vasto, tradição e composição étnico-racial plurais não concediam aos grupos/sociedades/povos da região uma roupagem homogênea dentro dos modelos herdados ou apropriados dos ex-colonizadores para a integração no pós-colonial.

Talvez, a aposta na localização de uma imagem a ser arrancada do espelho identitário e dos espaços da memória angolana, permitisse o tempo necessário para a recepção e internalização de uma identidade nacional. Um dos múltiplos ingredientes empregados nessa fórmula (provavelmente não o mais relevante) foi a preservação de uma memória sobre o outro/colonialista como opressor, invasor e usurpador.

Passados mais de trinta anos daqueles efusivos dias que marcaram o embarque das últimas tropas portuguesas, seria preciso perguntar: $\mathrm{O}$ quanto do artifício do colonizador ainda se encontra inscrito no corpo e na mente do angolano? O quanto as lembranças sobre o colonialista aparecem como o melhor ingrediente para a produção do discurso e da identidade nacional angolana? Fanon e Bhabha respondem essas questões de forma mais competente. Deixemos as palavras finais com esses dois habilidosos intérpretes da condição humana. 
Relembrar nunca é um ato tranqüilo de introspecção ou retrospecção. É um doloroso re-lembrar, uma reagregação do passado desmembrado para compreender o trauma do presente. É essa memória da história da raça e do racismo, do colonialismo e da questão da identidade cultural, que Fanon revela com maior profundidade e poesia do que qualquer escritor. $\mathrm{O}$ que ele realiza, assim creio, é algo muito maior: pois, ao ver a imagem fóbica do negro, do nativo, do colonizado, profundamente entremeada na padronagem psíquica do Ocidente, ele oferece a senhor e escravo uma reflexão mais profunda de suas interposições, assim como a esperança de uma liberdade difícil, até mesmo perigosa: 'É através do esforço de recapturar e perscrutar o eu, é através da permanente tensão de sua liberdade, que os homens serão capazes de criar condições ideais de existência para um mundo humano". (BHABHA, 2003, p. 101-102)

\section{MIRRORS POSTCOLONIAL, COLONIAL IMAGES: DISCOURSES AND REPRESENTATIONS OF THE PORTUGUESE IN HISTORY TEXTBOOKS PRODUCED ANGOLAN AFTER INDEPENDENCE (1979-2000)}

Abstract: The article is intended to analyze part of the discourses and elaborate representations of the Portuguese in history textbooks produced and used in Angola during the period following the political independence of the country in 1975. The text presented, the result of a larger investigation, is referenced on the theoretical frameworks related to African Studies, Cultural Studies and the Postcolonial, to identify the form as part of the Angolan didactic production approved, promoted and disseminated the understanding of national identity and colonial and post-colonial relations with the Portuguese. From the listed assumptions selected for an initial reflection two books produced between 1979 and 2000 for the fourth grade of schooling.

Keywords: Identity. Post-Colonial studies. Angola. Teaching. Colonization.

Anos 90, Porto Alegre, v. 21, n. 40, p. 227-249, dez. 2014 
Espelhos pós-coloniais, imagens coloniais...

\section{Notas}

${ }^{1}$ MINISTÉRIO DA EDUCAÇÃO DA REPÚBLICA POPULAR DE ANGOLA (1979; 2000)

${ }^{2}$ Sobre a temática, consultar os seguintes artigos: Oliva (2009; 2003; 2011).

\section{Referências}

APPIAH, K. A. Na Casa de Meu Pai: a África na filosofia da cultura. Contraponto, Rio de Janeiro, 1997.

BARBOSA, M. F. Nação, um discurso simbólico da modernidade. Crítica Cultural, Palhoça, v. 6, n. 1, p. 203-216, jan./jun. 2011.

BHABHA, H. K. O local da cultura. Belo Horizonte: Editora UFMG, 2003.

CHATTERJEE, P. Colonialismo, Modernidade e Politica. Salvador: EDUFBA; CEAO, 2004.

FALOLA, T. Nacionalizar a África, culturalizar o Ocidente e reformular as humanidades na África. Afro-Asia, UFBA, n. 36, p. 9-38, 2007.

GILROY, P. Multicultura e Convivialidade na Europa Pós-Colonial. A Urgência da Teoria. Lisboa: Tinta da China; Fundação Calouste Gulbenkian, p. 167-188, 2007.

HALL, S. Da diáspora. Identidades e mediações culturais. Belo Horizonte: Editora da UFMG, 2009.

MBEMBE, A. As formas africanas de auto-inscrição. Revista Estudos Afro-Asiáticos, Rio de Janeiro, ano 23, n. 1, p. 171-209, 2001.

MINISTÉRIO DA EDUCAÇÃO DA REPÚPLICA DE ANGOLA. História, Iniciação à História, Ensino de Base, $4^{a}$ classe. Lisboa: Artes Gráficas/Galeria do Tempo; Luanda: INIDE-MED, 2000.

MINISTÉRIO DA EDUCAÇÃO DA REPÚPLICA POPULAR DE ANGOLA. Iniciação à História de Angola, Ensino de Base, $4^{a}$ classe. Luanda: ME; Plátano Editora, 1979.

OLIVA, A. R. Entre Conquistas e Descobertas: abordagens da história africana entre os séculos VII e XVIII nos manuais escolares portugueses. O ensino de bistória da Africa em debate: saberes, práticas e perspectivas. Goiânia: PUC de Goiás, 2011, p. $129-154$.

Anos 90, Porto Alegre, v. 21, n. 40, p. 227-249, dez. 2014 


\section{Anderson Ribeiro Oliva}

O que as lições de história ensinam sobre a África? Reflexões acerca das representações da história da África e dos africanos nos manuais escolares brasileiros e portugueses. Revista Solta a Voz, v. 20, p. 214-231, 2009.

. História da África nos bancos escolares: representações e imprecisões

na literatura didática. Estudos Afro-Asiáticos (UCAM. Impresso), Rio de Janeiro, v. 25, n.3, p. $421-461,2003$.

SÁ, A. L. A ideia de Pós-Colónia em cientistas sociais africanos na diáspora. $7^{\circ}$ Congresso Ibérico de Estudos Africanos, Anais eletrônicos, CEA-ISCTE, Lisboa, p. 1-9. 2010. Disponível em: <https://repositorio.iscte.pt/handle/10071/2308>. Acesso em: 20 dez. 2013.

Recebido em: 09/03/2014

Aprovado em: 28/07/2014 